\title{
Greeting from Chairman
}

Intellectual property is becoming increasingly important in Japan for the pursuit of sustainable economic growth. In February 2002, the Japanese Cabinet convened the Strategic Council on Intellectual Property, which, in July of the same year, put together the Main Strategic Principles of Intellectual Property.

The Intellectual Property Association of Japan (IPAJ) was established on October 11, 2003 in the course of this rapidly changing environment surrounding intellectual property issues. Our goal is to provide an open stage for the people in various fields to advance their studies in intellectual property. For this purpose we believe it is especially important to encourage the participation of researchers and engineers from companies and universities, and not just the experts in a narrow sense. We also plan to expand our research activities into interdisciplinary areas that cover science and technology, business administration, economics, etc. Corporate engineers taking part in IPAJ programs will thus have a chance to learn how to face the drastic changes related to intellectual properties.

Furthermore, we have setup subcommittee meetings, to which our members may attend freely, in order to tackle the following intellectual property issues: strategic concepts, international matters, life science, novel studies, industry-academia collaboration and venture business, human resource training, accounting and administration, industrial copyrights, technological standardization, etc.

Annual symposiums and research meetings are being held to announce the above research achievements, and academic journals will also be published regularly to introduce the reviewed and approved papers of such studies.

Recently, in some patent lawsuits, the Japanese courts awarded inventors with enormous royalty payments in compensation for their contributions, which is now shedding light on the questionable nature of the current service invention systems. These rulings have also greatly increased the public awareness of intellectual property rights, and for researchers and engineers to make the best of their inventions, a thorough understanding in such matters has become essential. It is also vital for the survival of Japanese industries to successfully patent and utilize unique ideas. Especially now in the twenty-first century, when research and development in fields such as biotechnology, IT, and nanotechnology are moving at accelerated speed, the laws governing intellectual property rights should be enacted without delay to accommodate the rapid changes in science and technology. Some of the many issues that we believe IPAJ may help in solving are the establishment of courthouses specializing in intellectual property and the prevention of technology imitations in Asia.

IPAJ is planning to publish its journals both in English and Japanese to announce research achievements made in the intellectual property category. The English version, consisting of papers approved by peer reviews, will be placed on our website. The Japanese version, which is intended to be a book of enlightenment, will be published in the form of a paper magazine. I take this opportunity to kindly call upon all members of IPAJ to consider submitting their contributions to our journals.

Chairman of IPAJ

Isao Karube 